\title{
Optical Matrix Device: Technical Aspects of a New Tool for the Detection and Recording of Small Nocturnal Aerial Targets
}

\author{
Michael Vorotkov ${ }^{1}$, Alexandra Sinelschikova ${ }^{2}$, Martin Griffiths ${ }^{3}$ \\ ${ }^{1}$ (Pulkovo Observatory, Saint-Petersburg) \\ ${ }^{2}$ (Biological Station Rybachy, Russia) \\ ${ }^{3}$ (Durrell Institute of Conservation and Ecology, University of Kent) \\ (Email: Sinelsch@bioryb.koenig.ru)
}

\begin{abstract}
The detection of flying targets in the night sky has provided interest for bird migration research over many years with methods largely dependent on moon watching or the use of radar and infrared camera. These methods lack the versatility of the system described in this paper which detects and automatically records aerial targets in the night sky of a size greater than $5 \mathrm{~cm}$ and at a distance of 100 to 1000 metres from the observer. The principle design features are first, an optical device for receiving images of targets on two high-sensitivity CCD matrices when illuminated by white light from searchlight beams and secondly, instantaneous parallactic electronic computation enabling the distance from device to target to be accurately measured, and sequential images of each target to be recorded to computer. The device has been tested on targets during the main seasonal nocturnal migration of birds and provides accurate image details of important target flight parameters including: altitude, linear size (wing span and body length), direction of flight (ground track), orientation of the body axis - heading, ground speed, wing-beat frequency, number of wing-beats in each series of beats, duration of the pause between each series of wing-beats, and type of flight trajectory. There are also the potential practical applications for aviation bird-strike at night as well as the remote monitoring of insects, bats and other targets of natural and artificial origin.
\end{abstract}

\section{KEY WORDS}

1. Electronic-optical device. $\quad 2$ Nocturnal bird migration.

1. INTRODUCTION. The search to solve the problem of detecting a small sized target moving in darkness at a considerable distance from the observer and to receive its visual image, has arisen from recent ornithological research investigating bird migration. The phenomenon of bird migration has been actively studied by ornithologists over the last 100 years (e.g. Moreua 1972 and Berthold 2001) with about $80 \%$ of bird species of North America, Europe and Asia demonstrating 
various forms of migratory behaviour (Curry-Lindahl 1982). Research work has focused on key problems of orientation and navigation, energy expenditure and mechanics of flight, as well as mechanisms for the control of period and pattern of migration by internal and external factors. Methods involve natural observation, laboratory experiment and theoretical investigation. Direct observations of birds aloft focus on determining species composition and numbers of migrants, seasonal and daily temporal patterns of passage, height distribution, flight direction and the association with weather, especially wind direction and strength. Of particular importance, more than half of the species nesting in the Northern hemisphere migrate nocturnally and as a consequence are difficult to detect (Hansen 1954, Taylor 1972). Migration at night is typical for many waterfowl, waders, and especially passerine birds (Martin 1990) with a size range of 10-50 cm and airspeed 5-20 m/s. In the flat countries of Europe and North America a bulk of passerines (70-80\%) fly under the altitude of one kilometre (Zehnder et al. 2001, Bolshakov et al. 2002, Gauthreaux and Livingston 2006).

There are various recent techniques for the detection of birds flying at night and observing their flight characteristics. Their main features, presented in Table 1, show differences in the distance of bird detection, accuracy of species or group identification, weather-related limitations and number of detectable parameters. The main problem of nocturnal migration research is the absence of an accurate method for species identification which includes many required parameters at a relatively low cost. Because the stream of nocturnal migrants usually consists of dozens of species which may differ by their migratory directions, altitudes, flight abilities and migratory strategies it is an advantage to distinguish in particular species or groups of species similar in their taxonomy and ecology. The known methods, including radar, practically do not permit us to perform this task and there are doubts that this problem could be technically solved by radar equipment in the near future (Liechti 2007).

Presented here are the results of four years of joint experimental research work at the Biological Station Rybachy and the Pulkovo Astronomical Observatory, culminating in the design and testing of this new system for the detection and recording of nocturnal aerial targets. The images and the significant parameters attainable using this equipment we believe will constitute a significant step forward in bird migration research.

2. DEVICE DESIGN BACKGROUND. The background to the design of a suitable device to meet the needs for further advances in this field of biological research necessitated successfully meeting the required tasks and addressing the contradictory concerns arising from these tasks.

2.1. Requirements for the device. The following requirements for further advances have influenced our design during the development of this device:

- To create a clear image of a flying target to ensure adequate accuracy of measurement of its linear size.

- To collect and store statistically representative data.

- To monitor continuously the migratory activity through a series of complete nights at frequent sample dates throughout the migration seasons. 
Table 1. Comparison of nocturnal migration research methods.

\begin{tabular}{|c|c|c|c|c|c|c|}
\hline Method & $\begin{array}{l}\text { Surveillance } \\
\text { Radar }\end{array}$ & $\begin{array}{l}\text { Tracking } \\
\text { Radar }\end{array}$ & $\begin{array}{c}\text { Infrared } \\
\text { Thermal-imaging } \\
\text { camera }\end{array}$ & $\begin{array}{c}\text { Moon- } \\
\text { watching }\end{array}$ & Ceilometer & $\begin{array}{l}\text { Matrix } \\
\text { device }\end{array}$ \\
\hline Bird/non bird & - & indirectly & + & + & + & + \\
\hline $\begin{array}{l}\text { Species/group } \\
\text { identification }\end{array}$ & - & indirectly & - & + & + & + \\
\hline Size & - & size classes & - & + & + & + \\
\hline Altitude & $>100 \mathrm{~m}$ & $50 \mathrm{~m}-4 \mathrm{~km}$ & $100 \mathrm{~m}-3-5 \mathrm{~km}$ & $2 \mathrm{~km}$ & $\leqslant 500 \mathrm{~m}$ & $100-1000 \mathrm{~m}$ \\
\hline $\begin{array}{l}\text { Quantitative } \\
\text { migrant density }\end{array}$ & - & - & + & + & + & + \\
\hline Flight direction (track) & + & by tracking & + & + & + & + \\
\hline Heading (body axis) & - & - & - & - & - & + \\
\hline Ground speed & + & + & - & - & - & + \\
\hline Wing beat pattern & - & + & - & - & - & + \\
\hline Limitations & rain & rain & $\begin{array}{l}\text { low or partly } \\
\text { overcast, rain }\end{array}$ & $\begin{array}{l}\text { Moon cycle, } \\
\text { overcast, rain }\end{array}$ & $\begin{array}{l}\text { overcast, } \\
\text { fog, rain }\end{array}$ & $\begin{array}{l}\text { rain, low overcast, } \\
\text { twilights }\end{array}$ \\
\hline Main literature cited & $\begin{array}{l}\text { Lack \& Varley } 1945 \\
\text { Richardson } 1979 \\
\text { Gauthreaux 1974, } 1992 \\
\text { Gauthreaux \& Belser } \\
2003\end{array}$ & $\begin{array}{l}\text { Schaefer } 1968 \\
\text { Bruderer } 1999 \\
\text { Alerstam \& } \\
\text { Gudmundsson } 1999\end{array}$ & $\begin{array}{l}\text { Zehnder et al. } 2001 \\
\text { Gauthreaux \& } \\
\text { Livingston } 2006\end{array}$ & $\begin{array}{l}\text { Bolshakov } 1985 \\
\text { Bruderer \& } \\
\text { Jenni } 1990 \\
\text { Liechti } 2001 \\
\text { Baushev \& } \\
\text { Sinelschikova } \\
2007\end{array}$ & $\begin{array}{l}\text { Gauthreaux } 1969 \\
\text { Able \& Gauthreaux } \\
1975 \\
\text { Bolshakov et al. } 2002\end{array}$ & \\
\hline
\end{tabular}

+ possible to define or measure, - not possible to record the parameter. 
- To catalogue the following main flight parameters for each recorded bird:
Altitude.
Linear size.
Direction of flight.
Orientation of the body axis.
Ground speed.
Wing-beat frequency and its variation.
Number of wing-beats in each series of beats.
Duration of the pause between series of beats.
Type of flight trajectory.

The principle system design used to meet these requirements is a parallactic computation of the distance from the matrix device to the target. This enables the subsequent calculation of the target linear size from known distance and its angular dimensions; the ground speed from the angular displacement for known time interval; the dynamic characteristics of the target and its orientation in space from the pattern of trajectory with a sequence of the instantaneous images.

2.2. Main concerns taken into account. The main concern was to overcome the contradiction between the need for high angular resolution to ensure the required accuracy of measurements on the one hand and the need for a wide field of vision on the other to achieve a statistically representative sample of targets and to consider trajectory type.

There was also the requirement for an instantaneous clear image while at the same time revealing information on target movement for an adequate period of time.

The large dynamic altitude range creates one-hundred-fold variation in the illumination of the observed targets. This results in over-illuminated images at low altitude but poor detail of images of high flying targets in the same exposure.

The dispersed light from the lowest strata of the column of light and the light spot on the clouds cause background flare.

Finally, real-time storage creates a huge volume of crude data. On the one hand the material from continuous monitoring negates the standard procedure of compression with consequent loss of information (e.g. conversion to *.avi or similar formats); the rate of data receipt is also much higher than the rate of preliminary processing. On the other hand the recording and saving of a huge flux of crude data demand very high computer resources.

Despite these concerns, after experiments and modelling it became possible to find some original technical solutions. These solutions have defined the design of the system device.

3. DESIGN SOLUTiOnS FOR THE DEVICE. The Optical Matrix Device consists of two main components: the recording unit (electronic-optical system) and the illumination system.

3.1. The Recording Unit. See Figure 1. The image of an object, under artificial illumination of white light in the visible range of wavelength, is received on two highsensitivity CCD matrices. The optical system consists of two channels with parallel optical axes separated from each other at the locating distance by 1 metre. Each channel includes a high-quality objective lens, a heating anti-condensation system, an 


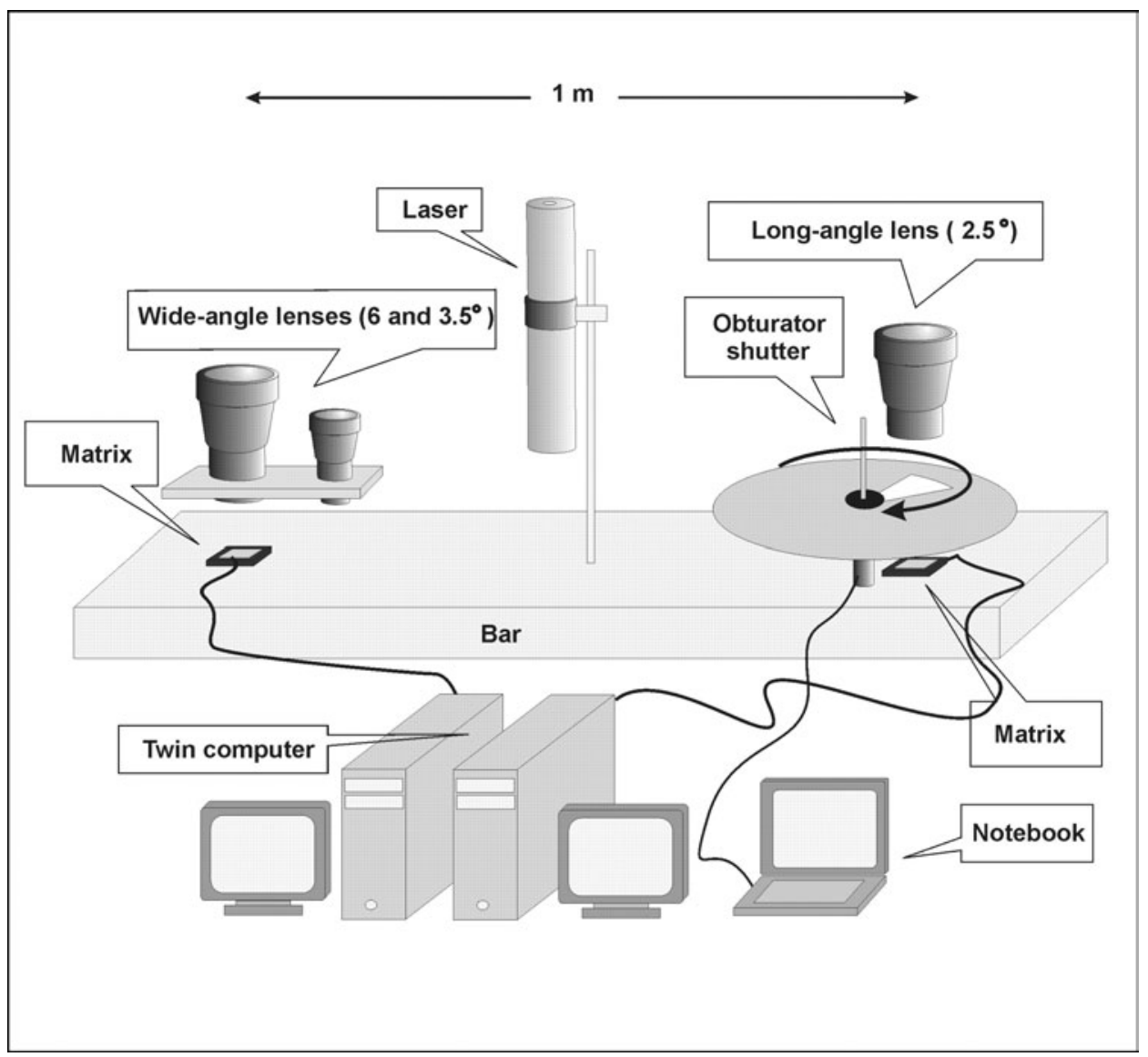

Figure 1. The Recording Unit (electro-optical system).

image focusing unit, a CCD matrix and a video board (grabber). The objective lenses are interchangeable and have different focal distances. In this project we used three lenses with the following parameters:

1. $\mathrm{F}$ (focal length) $=50 \mathrm{~mm}\left(6^{\circ}\right), \mathrm{S}$ (focal length/aperture $)=1 \cdot 7$

2. $\mathrm{F}=86 \mathrm{~mm}\left(3 \cdot 5^{\circ}\right), \mathrm{S}=1 \cdot 5$

3. $\mathrm{F}=120 \mathrm{~mm}\left(2 \cdot 5^{\circ}\right), \mathrm{S}=1 \cdot 8$.

Their combination determines angular resolution and field of vision of the channels. The scales of the fields of vision differ by a factor of 1.5-2.5. Their centres are accurately superimposed by the laser beam. During the exposure time $(0 \cdot 3-1 \cdot 5$ seconds) a target usually passes an angular distance of $0 \cdot 25-5$ degrees depending on its altitude. One channel is equipped with an obturator (rotating) shutter which chops the track of an object into 10-50 instantaneous and sequential images within one frame. This clearly results in a method taking much less recording space than an analogous video sequence. The obturator shutter is servo controlled by an independent computer which allows the setting of an accurate speed of rotation and required time interval 


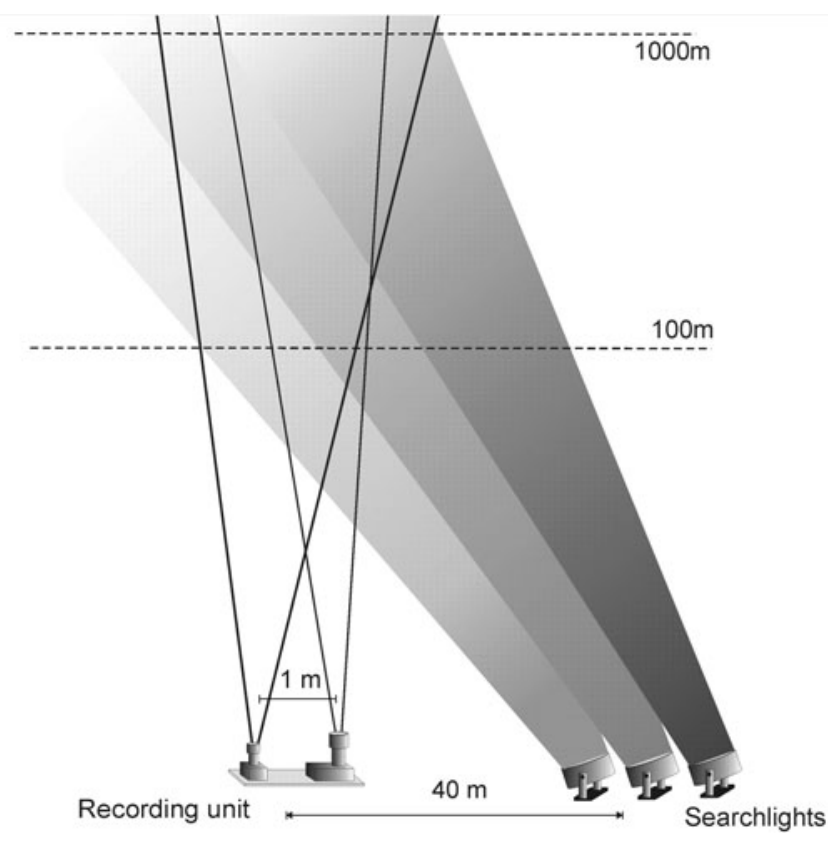

Figure 2. Arrangement of the recording unit and the illumination system.

between separate images with a duration of exposure of 25-18 milliseconds. The speed of rotation is optimized and governed on the assumption that the most probable speed of a bird at the moment of observation varies between 5 and 20 metres/ second, with an average of about $10 \mathrm{~m} / \mathrm{s}$ (Bruderer \& Bold 2001). The second channel (with a wide field of vision) works without shutter and forms the image as a target track of variable width and brightness.

Imaging is created independently by two synchronized computers on the information received from the video boards at the end of the exposure sequence. The images are written to the hard discs in a specific format. Besides the frame each file saves information on the moment of time of exposure on the matrix, exposure sequence and other parameters of the obturator etc., which are required for the subsequent processing. Total data flux per night is about 50,000 files of total volume $25 \mathrm{~Gb}$. To provide uninterrupted monitoring, the system works automatically throughout the night. Control and data input is performed by a special twin computer. The further data analyses are processed after the crude data collection.

3.2. The Illumination System. The illumination system is installed $40 \mathrm{~m}$ apart from the recording unit (See Figure 2). The system consists of three searchlights of differing luminance and angular size. OSRAM lamps of 250-400 W were used in this project. The parabolic mirrors installed in each searchlight permit the separate focusing of the light beams. The searchlight unit forms one combined beam with an open angle of $5^{\circ}$. Mutual alignment of the beams, their combination (switched on 1 to 3 searchlights simultaneously) and their position relative to the optical axis of the recording unit can be adjusted depending on the altitude of the cloud canopy until the 
lowest brightest part of the beam and the spot of light on the clouds, appear to be out of field of vision. A zone of intersection of the cone of light and cone of vision then has lower and upper boundaries. Under perfect weather conditions they are of an altitudinal range of 100-1000 $\mathrm{m}$ where there is a uniform field of light.

Adjustment to the searchlights is a critical technique which requires preliminary computer simulation depending on the current weather conditions. To improve this procedure an additional adjusting searchlight was used which forms a reference grid in the night sky using three needle shaped beams. The beam direction is controlled on the screen of the computer of the optical system when the $6^{\circ}$ wide angle objective lens is installed.

4. APPROPRIATE SOFTWARE. For a successful operation of the system it was necessary to write dedicated software (Matlab 6.5). This provides complete multistep data processing, as follows:-

- A program package records and controls available crude data (the total volume per season of migration may exceed $1000 \mathrm{~Gb}$ ). The time sweep for the whole season of observation can be presented in an easy graphical form where any data set could be extracted directly.

- Visual examination of the frame flow is provided by a two-channel viewer.

- The frames of each channel have different scales. To measure the parallax the images should be matched with an error of not more than 10 angular seconds. The program automatically estimates relative displacement, rotation and coefficient of scale transformation of the images. The interface controls and corrects the spatial synchronization.

- The selected material is subsequently displayed appropriately for measurements. The images of both channels are superimposed and the measurement of all target parameters is accomplished semi-manually by draft designation of the graphics primitives which mark the control points of the image (see Figure 3). As a result the calculation of the required target parameters is achieved. For the birds we calculate the following parameters:- altitude, linear size (wing span and body length), direction of flight (ground track), orientation of the body axis - heading (the line tail-head), ground speed, wing-beat frequency, number of wing-beats in each series of beats, duration of the pause between series of beats, type of flight trajectory (straight, curved or other).

- The installed image handling controls allow the improvement of the picture of a target and the optimization of viewing parameters (brightness and contrast ratios etc.). It was also possible to identify targets by comparison with a set of the pattern images of the known birds.

- The position of the light spot on the cloud cover (lower than $2 \mathrm{~km}$ ) allows an estimate of the real altitude of clouds. In some cases by the moving fragments of clouds it is also possible to calculate wind speed and direction at the corresponding altitudes.

- The received data are catalogued in the database including for each recorded target the parameters of synchronization, instrumental parameters of the system (exposure, shutter parameters etc.). The interface enables easy navigation through the database. 


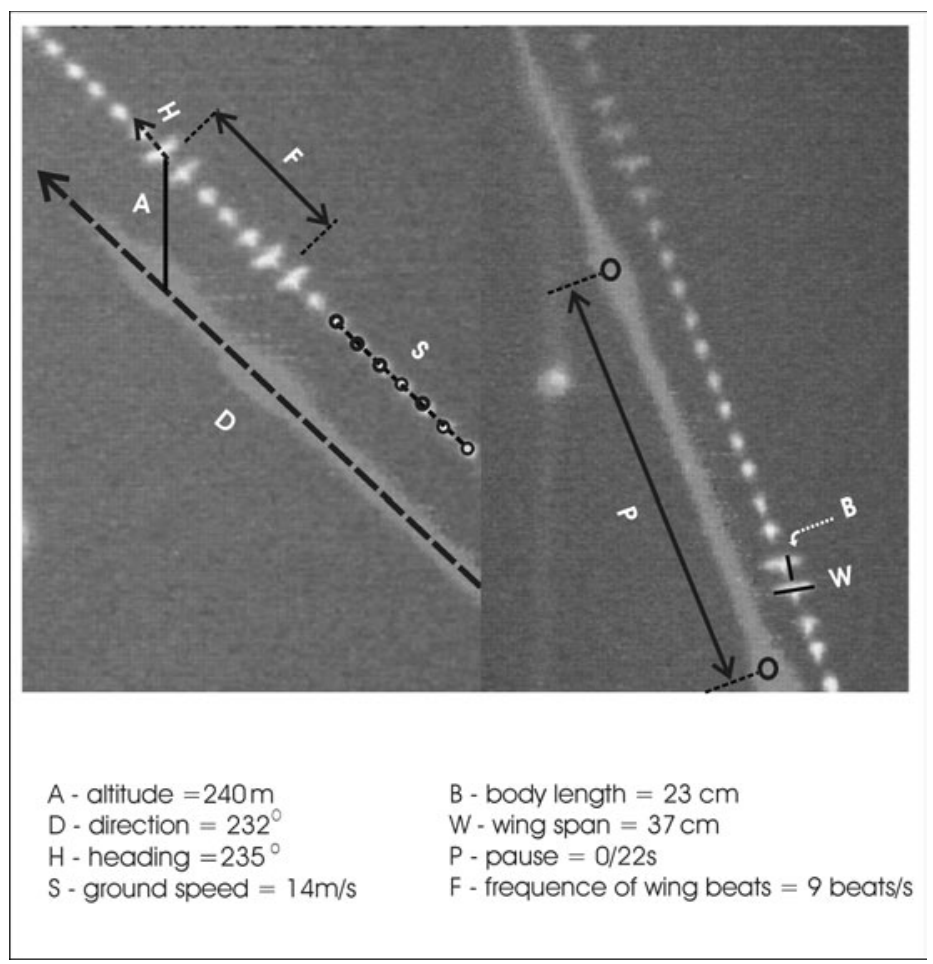

Figure 3. Photographs of the tracks of two individual birds (the Song Thrushes) recorded by the Optical Matrix Device illustrating the measurements taken of the linear and dynamic parameters recorded.

- An installed statistics module permits a direct initial summary of results in the form of diagrams and histograms.

5. TESTING THE SYSTEM. In autumn 2006 there was an initial field testing of the equipment. During 22 nights of observation 1537 targets were recorded and identified. Birds were identified for $1284(84 \%)$, insects $(6 \%)$, bats $(4 \%)$, satellites and artificial fragments $(6 \%)$. It was impossible to identify 168 targets. The field testing clarified the reliability of the device under real field conditions and confirmed the scientific validity of the data obtained for the study of bird migration (Vorotkov et al. in prep).

The system advantages are first, the ability to catalogue a representative volume of data throughout a night and throughout a migration season and second, the presentation of a wide range of the important parameters to help with the identification of species (or species group) as well as parameters of target ground track differing from heading showing the influence of wind direction.

The collected data were processed and considered for each parameter. The results were compared with those known in literature and gathered by alternative methods. It was shown that the collected data are largely in agreement with known published results (Vorotkov et al. in prep). We believe the system presented here to be a potential advance in technique for bird migration research. There are also the potential 
applications for bird-strike, with $80 \%$ of migrant species passing overhead at night and consequently a hazard to aircraft, as well as for the remote monitoring of insects, bats and other targets of natural and artificial origin such as space debris.

\section{ACKNOWLEDGEMENTS}

This study was supported by the Russian Foundation for Basic Research (grant to Casimir Bolshakov no. 08-04-01658). The authors are grateful to Casimir Bolshakov for the project initiation.

\section{REFERENCES}

Able, K.P. and Gauthreaux, S.A., Jr. (1975). Quantification of nocturnal passerine migration with a portable ceilometer. Condor, 77, 92-96.

Alerstam, T. and Gudmundsson, G.A. (1999). Migration patterns of tundra birds: Tracking radar observations along the Northeast Passage. Arctic, 52, 346-371.

Baushev, A.N. and Sinelschikova, A. (2007). On a probabilistic model for the numerical estimation of nocturnal migration of birds. Mathematical Bioscience, 205, 44-58.

Berthold, P. (2001). Bird Migration: a general survey (2nd ed). Oxford University Press, Oxford.

Bolshakov, C. (1985). Moon-watch method for quantitative studying of nocturnal bird passage (collection, calculation and analysis of data). pp. 260-294. In: V. Dolnik, (Ed.), Spring nocturnal bird passage over arid and mountain areas of Middle Asia and Kazakhstan, Academy of Sciences, Leningrad.

Bolshakov, C., Žalakevičius, M. and Švažas, S. (2002). Nocturnal migration of thrushes in the Eastern Baltic region. Vilnius.

Bruderer, B. (1999). Three decades of tracking radar studies on bird migration in Europe and the Middle East. Proceedings of the International Seminar on Birds and Flight Safety in Middle East, Tel-Aviv, Israel.

Bruderer, B. and Jenni, L. (1990). Migration across the Alps. Pp 60-77. In E. Gwinner, (Ed), Bird migration: the physiology and ecophysiology, Springer-Verlag, Berlin.

Bruderer, B. and Bold, A. (2001). Flight characteristic of birds: I. radar measurements of speed. Ibis, 143, 178-204.

Curry-Lindahl, K. (1982). Das große Buch vom Vogelzug. Parey, Berlin.

Gauthreaux, S.A., Jr. (1969). A portable ceilometer technique for studying low-level migration. Bird banding, 40, 309-320.

Gauthreaux, S.A., Jr. (1974). The detection, quantification, and monitoring of bird movements aloft with airport surveillance radar (ASR). Proceedings of a Conference on the Biological Aspects of the Bird-Aircraft Collision Problem (S. A. Gauthreaux, Jr., Ed.), Clemson University, Clemson, South Carolina.

Gauthreaux, S.A., Jr. (1992). The use of weather radar to monitor long-term patterns of trans-Gulf migration in spring. Pages 96-100 in Ecology and Conservation of Neotropical Migrant Landbirds (J. M. Hagan III and D. W. Johnston, Eds.), Smithsonian Institution Press, Washington, D.C.

Gauthreaux, S.A., Jr. and Belser, C.G. (2003). Radar ornithology and biological conservation. The Auk, 120 (2), 266-277.

Gauthreaux, S.A., Jr. and Livingston, J.W. (2006). Monitoring bird migration with a fixed-beam radar and a thermal-imaging camera. J. Field Ornithology, 77(3), 319-328.

Hansen, L. (1954). Birds killed at lights in Denmark 1886-1939, Vidensk. Medd. naturh. Foren., Kopenhagen, 116, 269-368.

Lack, D., and Varley, G.C. (1945). Detection of birds by radar. Nature, 156, 446.

Liechti, F. (2001). Calibrating the moon-watching method-chances and limits. Avian ecology and behaviour, 7, 27-40.

Liechti F. (2007). Radar ornithology - past experiences and future challenges. Proceedings of the 6th Conference of the European Ornithologists' Union, Vienna.

Martin, G. (1990). Birds by night. London: T\&AD Poyser.

Moreua, R.E. (1972). The Palaearctic-African bird migration systems. Academic Press, London.

Richardson, W.J. (1979). Radar techniques for wildlife studies. National Wildlife Federation Scientific Technical Series, 3, 171-179. 
Schaefer, G.W. (1968). Bird recognition by radar: A study in quantitative radar ornithology. Pages 53-86 in The Problems of Birds as Pests (R. K. Murton and E. N. Wright, Eds.), Academic Press, London.

Taylor, W.K. (1972). Analysis of Ovenbirds killed in central Florida. Bird-Banding, 43, 15-19.

Vorotkov, M., Sinelschikova, A. and Griffiths, M. Advantages of Optical Matrix System for the detection and identification of nocturnally migrating birds. In preparation.

Zehnder, S., Åkesson, S., Liechti, F. and Bruderer, B. (2001). Nocturnal autumn bird migration at Falsterbo, South Sweden. J. of Avian Biology, 32, 239-248. 